\title{
THE CASTIANEIRINAE OF MEXICO. I. CASTIANEIRA DUGESI (BECKER) (ARANEAE: CLUBIONIDAE)*
}

\author{
By Jonathan Reiskind \\ Department of Zoology, University of Florida, \\ Gainesville, Florida 326 I I
}

Since the revision of the Castianeirinae of North and Central America (Reiskind, 1969) new collections have been made and studied. This is the first of a series of papers that will update the Mexican component of this subfamily.

Castianeira dugesi (Becker) has been known from a single male described almost a century ago. Recent collections from locations within 50 miles of the type locality have produced additional specimens including the first females. C. dugesi is the nominal species in the dugesi species-group (which also includes $C$. nanella Gertsch and C. alfa Reiskind), a group restricted to the dry regions in southwestern U. S. and northwestern Mexico and characterized by its moderately small size, lack of plumose setae, and distinctive genitalia (Reiskind, 1969). As is characteristic of many ant mimicking species of Castianeira with no distinct morphological separation of cephalic from thoracic region the cephalic region in $C$. dugesi is marked off by color pattern which we can assume reflects the color pattern of the model ant.

\section{Castianeira dugesi (Becker)}

\section{Figures I-3}

Micariaulax dugesii Becker, 1879, Ann. Soc. Entomol. Belgium, 22: 83, pl. 2, fig. 9, 10, $\hat{\sigma}$, from Guanajuato, Mexico; in the Brussels Museum.

Castianeira dugesii: Simon, 1897, Histoire Naturelle des Araignées 2(1) : 167.

Castianeira dugesii: F. P.-Cambridge, 1899, Biol. Centrali-Americana. Arachnida 2: 81 .

Castianeira dugesii: Reiskind, 1969, Bull. Mus. Comp. Zool. 138(5) : 223225, pl. 10, fig. 127, 128.

\section{FEMALE}

Measurements. Based on two females: carapace length 2.65$2.70 \mathrm{~mm}$; carapace width $1.70-1.75 \mathrm{~mm}$; carapace index (carapace width $\div$ carapace length $\times$ IOO) 64 ; sternum length $1.15 \mathrm{~mm}$;

*Manuscript received by the editor February 28, 1974 

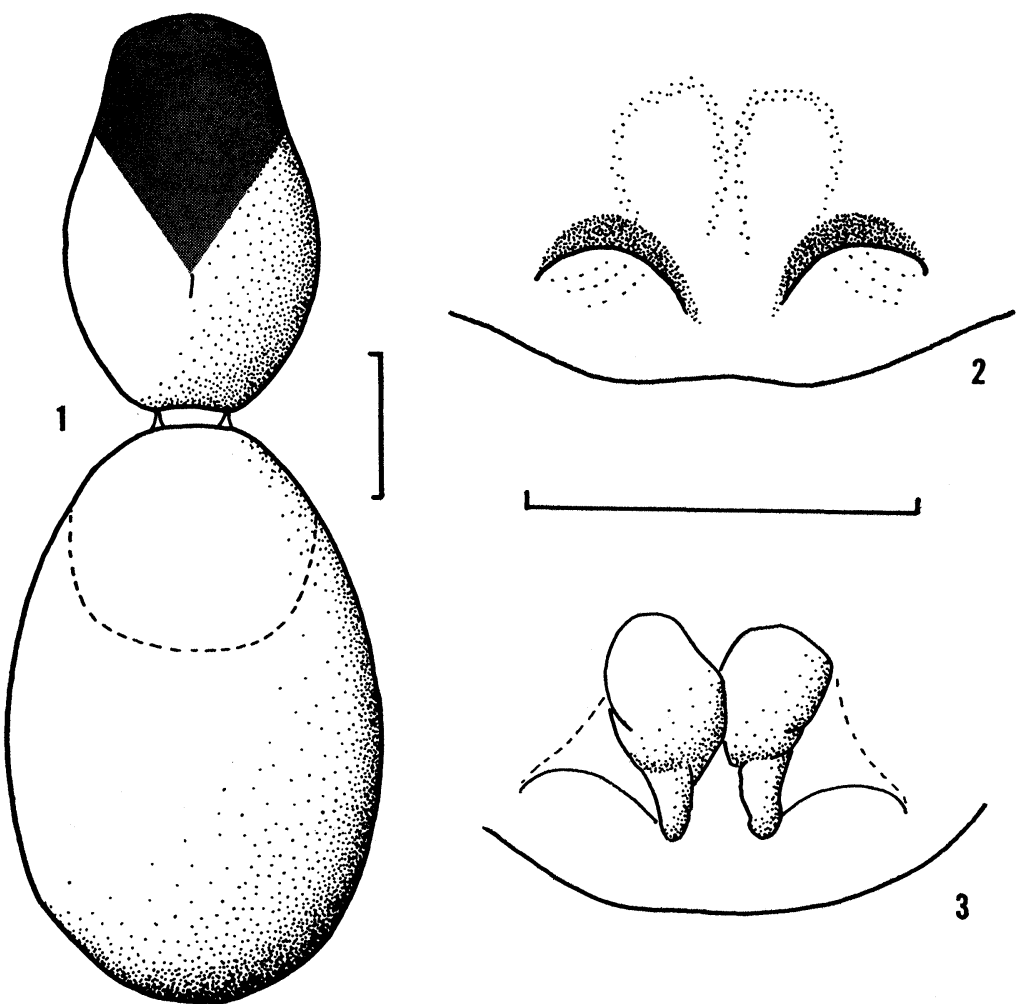

Figures 1-3. Castianeira dugesi (Becker). Fig. 1. Dorsal aspect of female. Pattern division of carapace shown by shading. (Vertical scale line $=1.0 \mathrm{~mm})$ Fig. 2. External epigynum. Fig. 3. Internal epigynum, dorsal view. (Horizontal scale line for epigyma $=0.5 \mathrm{~mm}$ ) 
sternum width $0.95 \mathrm{~mm}$; sternum index (width $\div$ length $\times$ IOO) 80 .

Femur IV length $1.75^{-1.85} \mathrm{~mm}$; femur IV width $0.45-0.55 \mathrm{~mm}$; leg thickness index (femur IV width $\div$ femur IV length $\times$ IOo) 26-29; leg length index (femur IV length $\div$ carapace length $X$ IOO) 67.

Abdomen length $4.00 \mathrm{~mm}$; abdomen width $2.30-2.35 \mathrm{~mm}$; abdomen index (width $\div$ length $\times$ IOO) $57-58$.

Description. Carapace orange-brown and hairless, with cephalic region dark brown (Fig. I). Carapace moderately narrow in head region (width at level of second eye row 0.59-0.6I times the maximum width of the carapace) and smoothly truncated anteriorly. Eyes moderately small, equal with posterior row somewhat wider than anterior. Distinct thoracic groove.

Abdomen oval, grey-brown, with a large anterior dorsal dark red-brown scutum (about one-third the length of the abdomen) (Fig. I) ; covered with sparce, fine setae. Epigastric and small inframammiliary scuta red-brown. Both pairs of anterior abdominal setae hairlike.

Sternum orange-brown with light, thin setae.

Chelicerae dark-brown (like cephalic region of carapace) with two moderate retromargin teeth and two slightly larger promargin teeth. Pedipalps with red-brown femur and rest yellow.

Coxa I yellow-brown, rest of coxae yellow. A small notch on trochanter IV.

Femur I dark brown with yellow distal end, rest of leg I and leg II and III yellow; leg IV dark yellow with orange metatarsus. Tibia I ventral spination: 2 (prolateral)-2 (retrolateral) and small.

External genitalia with a pair of wide, flared openings (Fig. 2). Internal structure with globose spermathecae drawn out into narrow straight posterior necks (Fig. 3).

MALE

Measurements. Based on two males: carapace length $2.05 \mathrm{~mm}$; carapace width $\mathrm{I} .25 \mathrm{I} .30 \mathrm{~mm}$; carapace index 6I-63; sternum length 0.95-1.00 mm; sternum width $0.75 \mathrm{~mm}$; sternum index 73-77.

Femur IV length I.4O-I.45 mm; femur IV width $0.35 \mathrm{~mm}$; leg thickness index 24-25; leg length index 69-7 $\mathrm{I}$.

Abdomen length 2.45-2.60 mm; abdomen width $1.15 \mathrm{~mm}$; abdomen index 45-47.

Embolus length $0.06-0.07 \mathrm{~mm}$; genital bulb length $0.63-0.65 \mathrm{~mm}$; male genital index (embolus length $\div$ bulb length $\times$ IOO) 9.5-10. 
Description. Similar to female with the following differences: Only the anterior portion of carapace cephalic region dark-brown. Abdomen with a full scutum, granulose at anterior end and gradually becoming smooth and shiny posteriorly. Tibia I ventral spination: $\mathrm{I}-\mathrm{O}$ and small. Genital bulb drawn out into a long neck ending with an embolus having a right angle near tip (illustrated in Reiskind, 1969).

Diagnosis. C. dugesi differs from other dugesi group members in its genitalia (right angle at end of male embolus and straight spermathecal necks), distinct patterns of carapace and legs.

Distribution. Apparently this species is restricted to a small region of central Mexico in northeastern Jalisco and Guanajuarto states.

Records. mexico. Guanajuarto. Jallisco: $10.8 \mathrm{mi}$. S. Talpa de Allende, 4900', 8-VIII-67 (R. E. Leech); I3 mi. SE. Lagos de Moreno, 6450', 7-IX-67 (R. E. Leech, G. E. Ball).

The female of Castianeira dugesi would key out to couplet \#36 in the Key to the Females of Castianeira in Reiskind (1969). It can then be separated from the other species included in that couplet by its dark abdomen and bicolored carapace.

I wish to thank Dr. Robin E. Leech for the generous loan of the specimens studied in this paper.

\section{Literature Cited}

Reiskind, J.

1969. The Spider Subfamily Castianeirinae of North and Central America (Araneae, Clubionidae). Bull. Mus. Comp. Zool. 138(5): 163-325. 

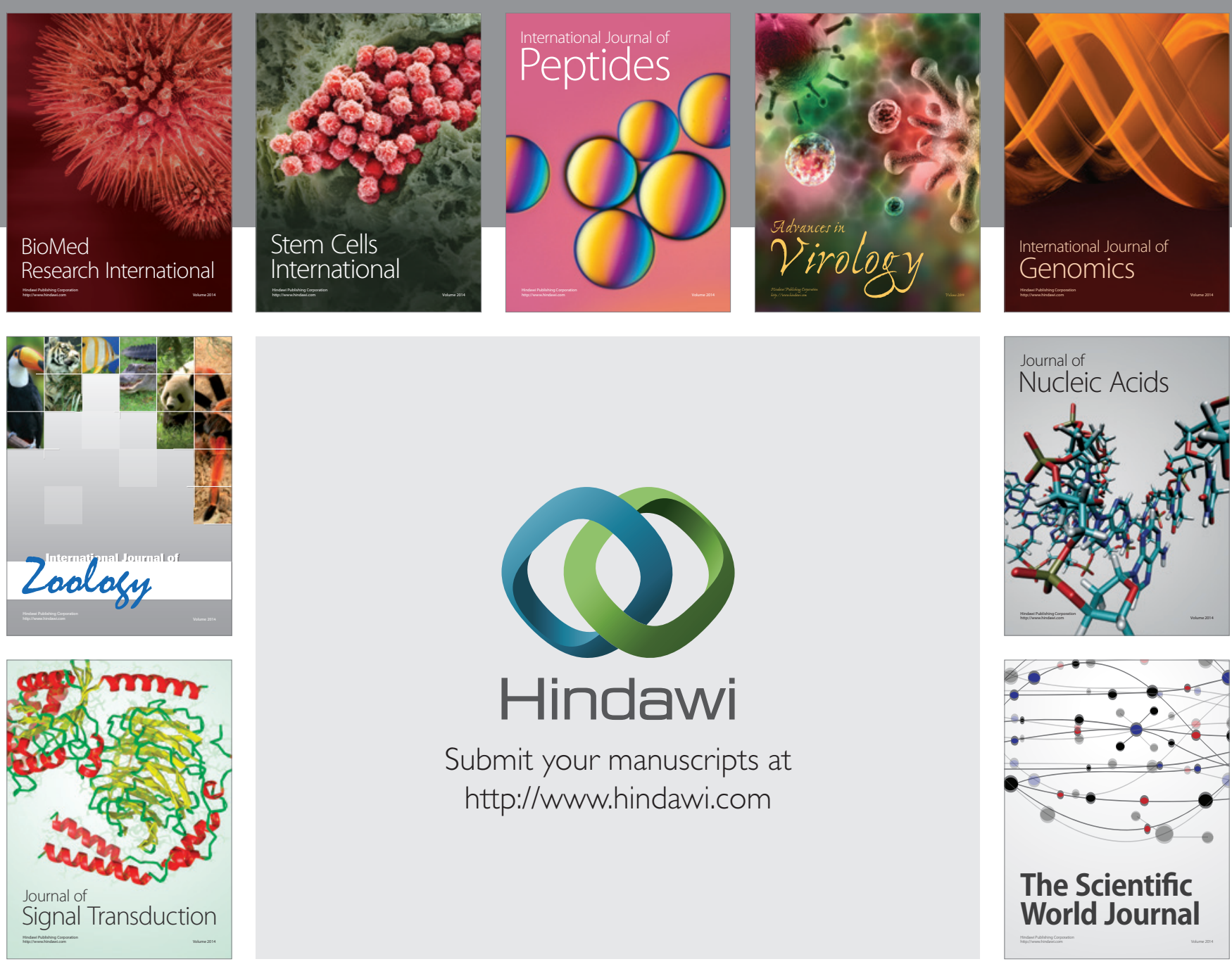

Submit your manuscripts at

http://www.hindawi.com
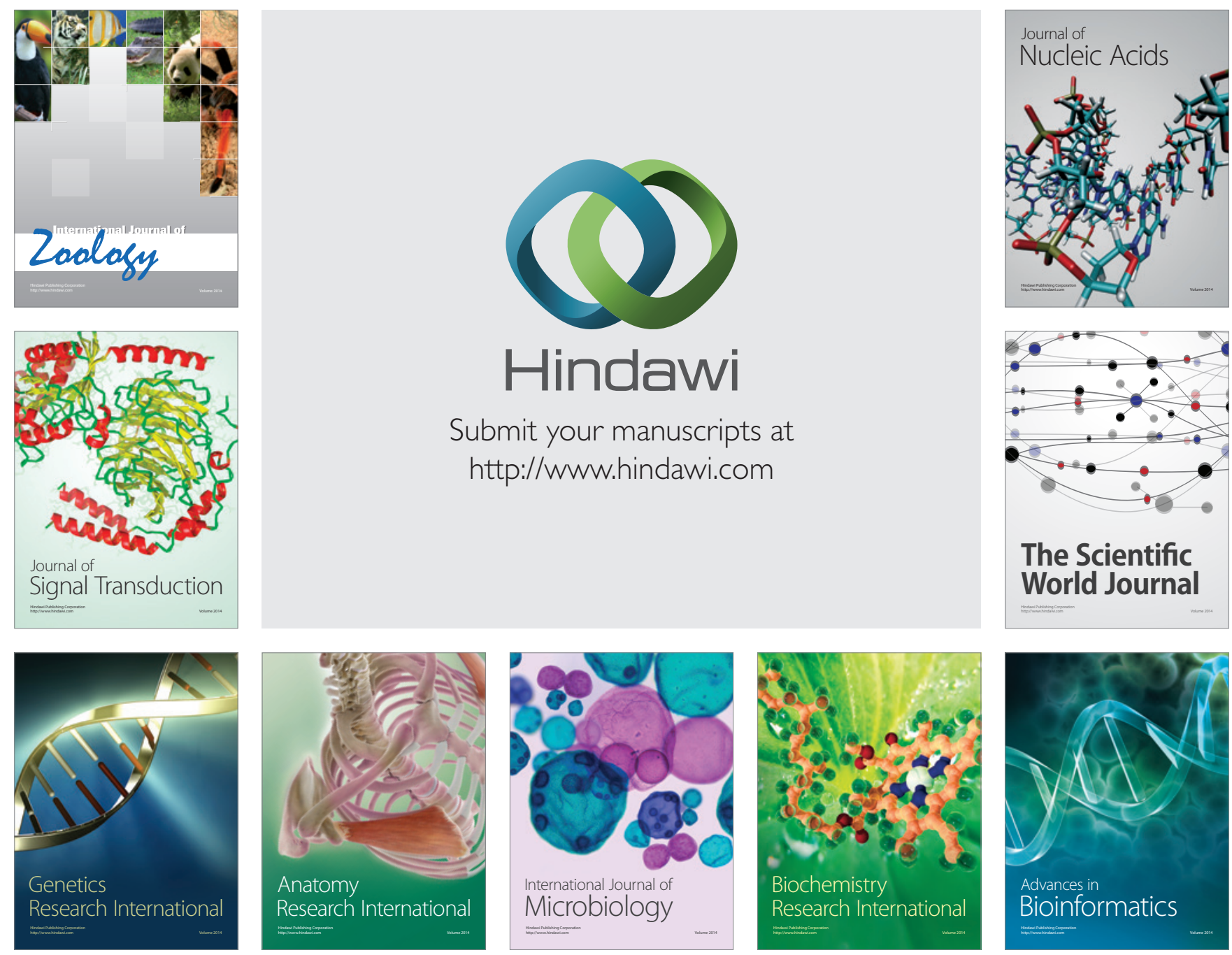

The Scientific World Journal
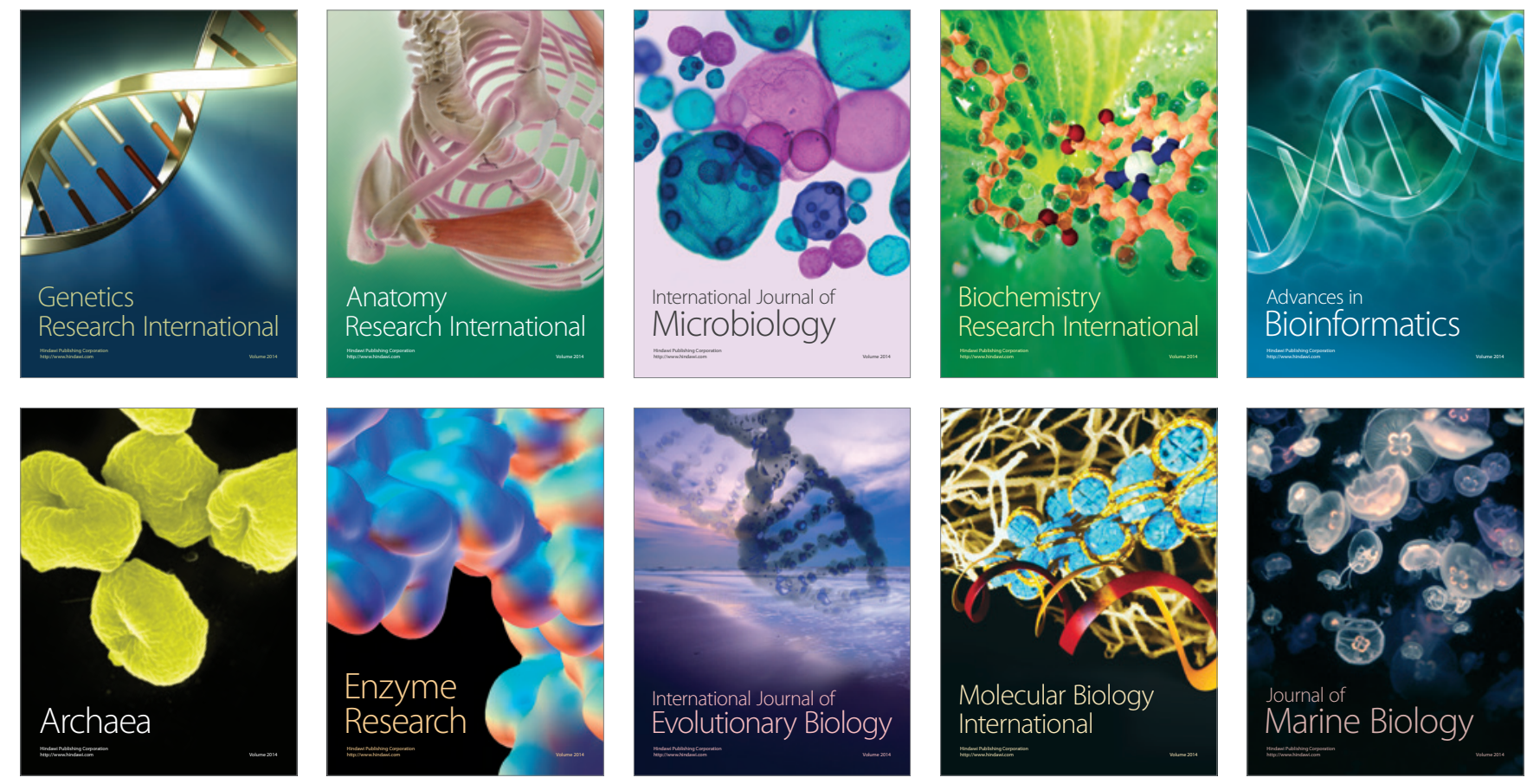